\title{
Determination the effectiveness of a selected formulations of Iranian traditional medicine "Ushaq poultice" (ammoniacum gum ointment) on wound healing: An experimental study
}

\author{
Zeinab Zaheri Abdevand', Amir Siahpoosh'1, Alireza Malayeri², Anayatollah Salami², Layasadat Khorsandi
}

\author{
1'Department of Pharmacognosy, Faculty of Pharmacy, Ahvaz Jundishapur University of Medical Sciences, Ahvaz, Iran. \\ 2Department of Pharmacology, Faculty of Pharmacy, Ahvaz Jundishapur University of Medical Sciences, Ahvaz, Iran. \\ 'Department of Pharmaceutics, Faculty of Pharmacy, Ahvaz Jundishapur University of Medical Sciences, Ahvaz, Iran \\ ${ }^{4}$ Department of Anatomical Sciences, Faculty of Medicine, Ahvaz Jundishapur University of Medical Sciences, Ahvaz, Iran \\ Corresponding Author: Zeinab Zaheri Abdevand (E-mail: zeinab.zaheri@yahoo.com) \\ (Submitted: 16 January 2020 - Revised version received: 10 February 2020 - Accepted: 07 March 2020 - Published online: 26 April 2020
}

\begin{abstract}
Objective Recent studies showed that this plant had antibacterial, antioxidant, and anti-inflammatory activities. The purpose of this study was to evaluate the therapeutic effects of ammonium gum ointment on wound healing in the animal model.

Methods Thirty-two (32) male Wistar rats were selected; then in non-infectious condition, 2 full-thickness wounds with 8 mm in diameter were created bilaterally on shaved skin in $1.5 \mathrm{~cm}$ from the dorsal midline and randomly divided into 4 groups: untreated group, phenytoin cream treated group, base ointment (sesame oil and wax) treated group and ammoniacum gum ointment (AGO) treated group. The animals received these medicines once daily. On days 5, 7, 10,12, and 14 wound area was measured. On days 7 and 14, blood samples were taken, and serum level of growth factors [epidermal growth factor (EGF), platelet-derived growth factor (PDGF), vascular endothelial growth factor (VEGF), and transforming growth factor- $\beta$ (TGF-B)] were measured. Skin samples used for hematoxylin-eosin and trichrome staining. Skin tensile strength and hydroxyproline content of skin tissues were also measured.

Results The percentage of wound healing after 14 days of treatment was significantly increased in the group receiving $A G O(P<0.05)$. Hydroxyproline content of repaired tissue and tensile strength increased considerably in this group $(P<0.001)$. Growth factors were significantly increased in animals treated with $A G O$ compared to control groups (EGF $P<0.05$; PDGF $P<0.001$; VEGF $P<0.001$; TGF-B $P<0.05)$. Histological data showed that the topical application of AGO compared to other groups resulted in positive effects on enhancing neovascularization and granulation, increased wound healing rate, and decreased wound size.

Conclusion The topical application of an ointment containing ammoniacum gum can help speed-up the process of wound healing. Keywords wound healing, Dorema ammoniacum gum, herbal medicine, experimental study
\end{abstract}

\section{Introduction}

Skin epithelium disruption occurs by disturbing the continuous functions of living tissues due to physical, chemical, thermal, immunological, and microbial factors in the wound. Wound healing is a complex process which, involves interactions between immunological and biological systems and includes a cascade of precise steps and events. ${ }^{2-4}$ Wound healing is no longer a generic term; instead, it is considered a series of carefully regulated and interrelated processes. ${ }^{5}$ These coordinated processes include hemorrhage, coagulation, initiation of acute inflammatory reaction induced by primary injury, remodelling, migration, and proliferation of connective tissue and parenchymal cells, as well as the synthesis of extracellular matrix proteins, new parenchymal remodelling and connective tissue and collagen deposition. Finally, in a regular procedure, increasing skin strength is performing and results in healing of the injured tissues. ${ }^{2}$

It has been proven that many herbal extracts accelerate the wound healing process through angiogenesis, ${ }^{6,7}$ activation of NF-kB, ${ }^{8}$ proinflammatory cytokines, ${ }^{9}$ iNOS,,${ }^{10}$ collagen alpha1 type I upregulation, ${ }^{11}$ the proliferation of fibroblasts, ${ }^{12}$ and antioxidant activity. ${ }^{9}$

In recent years, the concentration of researchers on complementary and herbal medicine has increased throughout the world. Iranian traditional medicine is one of the strongest branches of complementary medicine that could be used in phytotherapy. In Iranian traditional medicine manuscripts, special attention is paid to wounds and wound healing, and some headings assigned to this topic. ${ }^{13}$ Marham-e-ushaq is an ointment that is used in Iranian traditional medicine to heal various types of wounds. This ointment consists of ammoniacum gum (ushaq), sesame oil, and beeswax. The principle and perpendicular component of this product is ushaq (ammoniacum gum). ${ }^{13}$ When the ushaq gum is applied to the wound area, it can eliminate extra discharge from the wound site, remove corrupt tissues, grow healthy tissue to heal the wounds, and prevent scar formation on the injured site. ${ }^{14}$

The ushaq or ammoniacum gum is obtained from the Dorema ammoniacum, which is one of the most important herbs in the Apiaceae family. Six species of Dorema have been shown in the flora of Iran, in which two species are D. ammoniacum D. Don. and Dorema aucheri Boiss are endemic. Dorema ammoniacum grows in many arid and semi-arid regions of Iran including Yazd, Isfahan, and Semnan provinces and is known by the local Persian names such as Kandal, Vasha, or Camakandal. ${ }^{15,16}$

In The British Pharmacopoeia, the ammoniacum gum is known as antispasmodic and expectorant and used for chronic bronchitis and persistent coughing. ${ }^{17,18}$ In traditional medicine books, ammoniacum gum is widely used in the gastrointestinal, liver, respiratory, musculoskeletal, and skin disorders as a strong anti-inflammatory, absorbent, and drying agent. ${ }^{13}$ Recent studies show that this herb has antioxidant ${ }^{19}$, antiinflammatory, analgesic ${ }^{20}$, antimicrobial ${ }^{21}$, anticonvulsant ${ }^{22}$, AChE inhibitor ${ }^{23}$, and cytotoxic activity. ${ }^{24}$ 
In this experimental study, we demonstrated the wound healing potential of Marham-e-ushaq (ammoniacum gum ointment, AGO) on full-thickness skin wound model in Wistar rats and compared with control groups.

\section{Materials and Methods}

\section{Materials}

Dorema ammoniacum gum was purchased from a local herb store in Tehran, Iran. The gum was identified by the Pharmacognosy Department of Jundishapur University of Medical Sciences, Ahvaz, Iran. The sesame oil was purchased from Barij Co. with batch no. 612138055.

\section{Preparation of Topical Products}

Sesame oil and beeswax were warmed in a water bath and mixed. The ammoniacum gum powder (ushaq) was soaked in vinegar and stirred to smoothing. This compound was warmed in a water bath and added to warm oil and wax, stirred regularly for homogenizing and cooling. ${ }^{13}$

\section{Animals and Experimental Protocol}

32 male wistar rats weighing between 200 and 220 g were used in this study. Animals were obtained from the animal center of Ahvaz Jundishapur University of Medical Science. The animals were housed individually in separated metal cages at $22 \pm 1^{\circ} \mathrm{C}$, humidity $(60 \pm 5 \%)$, and a $12 \mathrm{~h}$ light/dark cycle, and they had free access to standard commercial pellet diet and tap water.

The experimental protocol was reviewed and approved by the Institutional Animal Ethics Committee (IR.AJUMS. ABHC.REC.1397.039).

The rats were anesthetized with intraperitoneal administration of ketamine-xylazine $(80 \mathrm{mg} / \mathrm{kg}: 5 \mathrm{mg} / \mathrm{kg})$. After shaving the hair on their back and disinfecting with $70 \%$ ethanol, two circular full-thickness skin wound ( $8 \mathrm{~mm}$ in diameter) was made at a distance of $1.5 \mathrm{~cm}$ from the midline of the back of each animal. After wounding, the rats were randomly divided (block randomization using the AABB method) into 4 groups of 8 animals and kept in separate cages. All cages were coded.

Treatment was started as following:

Group 1: Test group treated with AGO applied locally on wounds.

Group 2: Control group treated with phenytoin cream 1\% applied locally on wounds.

Group 3: Control group treated with ointment base (beeswax and sesame oil, 1:10) applied locally on wounds.

Group 4: Control group without treatment.

\section{The Wound Area Measurement}

After wounding in non-infectious conditions and taking pictures, the medicine was applied to the wound site from Day 0 (day of wounding) and this procedure repeated every 24 $\mathrm{h}$ until healing was complete. The measuring method of the wound area is as follows:

Animals were anesthetized and fixed in the standard position on a flat surface, a ruler placed next to the wound, and a photograph was taken by a digital camera, at a distance of
$15 \mathrm{~cm}$ from the wound (without zooming in). These conditions were the same for all animals during the experiment. Then by the Digimizer software, the wound area was measured and recorded. The following equation was used to calculate the percentage of wound healing: $:^{25}$

$$
\frac{A 0-A t}{A 0} \times 100
$$

Where $\mathrm{A} 0$ is wound area on the first day and At is wound area after time interval.

\section{Histopathological Study}

On the 7th and 14th day after the complete recovery of the wounds, the animals were sacrificed. The hair was completely shaved. The tissues were collected from all animals and encoded in $10 \%$ buffered formalin. After the sequence of processes such as dehydration, clearing, tissue infiltration, and tissue embedding in paraffin, five microns thickness were cut using a microtome and stained with Masson-trichrome (for detection of collagen fibers) and hematoxylin and eosin ( $\mathrm{H} \& \mathrm{E}$ ) (for morphological observations). Tissues samples were evaluated qualitatively for the following histological criteria: the extent of re-epithelization, inflammation, neovascularization, the degree of granulation tissue formation, and collagen disorganization.

\section{Hydroxyproline Assay}

A certain amount of fresh tissues were weighed, and then samples were hydrolyzed with $6 \mathrm{~N}$ hydrochloric acid for $2 \mathrm{~h}$ at $120^{\circ} \mathrm{C}$. The $\mathrm{pH}$ of hydrolyzed samples reached to 7 and subjected to oxidation with chloramine T. Colored complex with an Erelich reagent at $60^{\circ} \mathrm{C}$ is read at $550 \mathrm{~nm}$ with spectrophotometer (SPEKOL 2000). The values of tissue weight are expressed in $\mu \mathrm{g} / \mathrm{mg}^{26,27}$

\section{Tensile Strength Measurements}

The tensile strength indicates tissue integrity. To measure the tensile strength, on the 7th and 14th day, a part of the restored skin is striped with a width of $5 \mathrm{~mm}$ and its strength was measured with a tensiometer device. ${ }^{28}$

\section{Growth Factors Assay}

On the 7th and 14th day, under sterile conditions, blood samples were taken directly from the heart of the animals. The blood samples were centrifuged at $1000 \mathrm{rpm}$ for $15 \mathrm{~min}$ and then stored at $-80^{\circ} \mathrm{C}$ until the test was performed. The level of transforming growth factor- $\beta 1$ (TGF $\beta 1$ ), platelet-derived growth factor (PDGF), epidermal growth factor (EGF), and vascular endothelial growth factor (VEGF) in serum samples was measured by ELISA, based on the manufacturer's instructions.

\section{Statistical Analysis}

Data are expressed as mean \pm standard error of the means (S.E). Statistically significant differences were determined using oneway analysis of variance (ANOVA) with the LSD post hoc for multiple comparisons. For all tests, the values of 
$P \leq 0.05$ were considered as statistically significant. Statistical analyze were performed using the SPSS statistical software (version 16.0 for Windows, SPSS Inc., Chicago, IL, USA).

\section{Results}

\section{Effect of Ammoniacum Gum on Wound Healing}

The process of wound healing in each group is shown in Fig. 1. The data show that the topical application of AGO promotes wound contraction with a reduction in wound area. The wound area was measured using Digimizer at $0,5,7,10$, 12 , and 14 days after wounding. Reduction in wound area was observed more rapidly with the topical application of AGO. The wound healing percentage of animals treated with AGO was significantly increased compared to control groups at days 5,7,10, and 12 after wounding (at Day 5: $P<0.01$ vs untreated and base ointment group; at day7: $P<0.05$ vs untreated and $P<0.01$ vs base ointment group; at day $10: P<0.05$ vs untreated and $P<0.01$ vs phenytoin and base ointment group; at day 12 : $P<0.05$ vs phenytoin and base ointment group) (Fig. 2). On Day 12, all animals in the AGO group were completely healed. There was a significant difference in wound healing between the AGO-treated group and base ointment treated at 14 days $(\mathrm{p}<0.05)$. Serious infection was not observe in all animals.

\section{Histopathological Study}

On the 7th day after wounding, the AGO-treated group showed a significant increase in granulation compared to the untreated and base ointment-treated groups $(P<0.05)$. In the group treated with AGO, the thickness of granulation tissue was uniform. There was no significant increase in vascularization in this group compared to the untreated and phenytoin treated groups. Inflammation in this group was significantly lower than the control groups $(P<0.05)$ (Figs. 3 and 5). At the end of the first week of treatment, epithelialization was not observed in any of the experimental groups.

On the 14th day, the wound surface in all groups coated with freshly epidermal tissue, and keratinization observed, and the thickness of the epithelium layer was uniform in the AGO treated group. (Fig. 5) The AGO-treated group showed no significant difference in the amount of granulation and vascularization compared to the phenytoin treated and untreated groups. Edema and inflammation decreased in all groups and this reduction in inflammation were significantly higher than untreated $(P<0.001)$ and base-treated groups $(P<0.01)$. (Figs. 4 and 5)

Trichrome staining in all groups indicated the formation of collagen strands and increased organization and reduction of irregularities in collagen fibers. The collagen disorganization significantly decreased in the AGO-treated group compared to the untreated group $(P<0.05)$. (Fig. 6)

\section{Tensile Strength Measurements}

The results of this study showed a significant increase in tensile strength in the AGO-treated group compared to the untreated and phenytoin-treated groups $(P<0.001)$. The results are shown in Table 1.

\section{Hydroxyproline Assay}

The results of this study showed that on the 7 th day after wound healing, the amount of hydroxyproline increased significantly in the group received AGO compared to the untreated and the

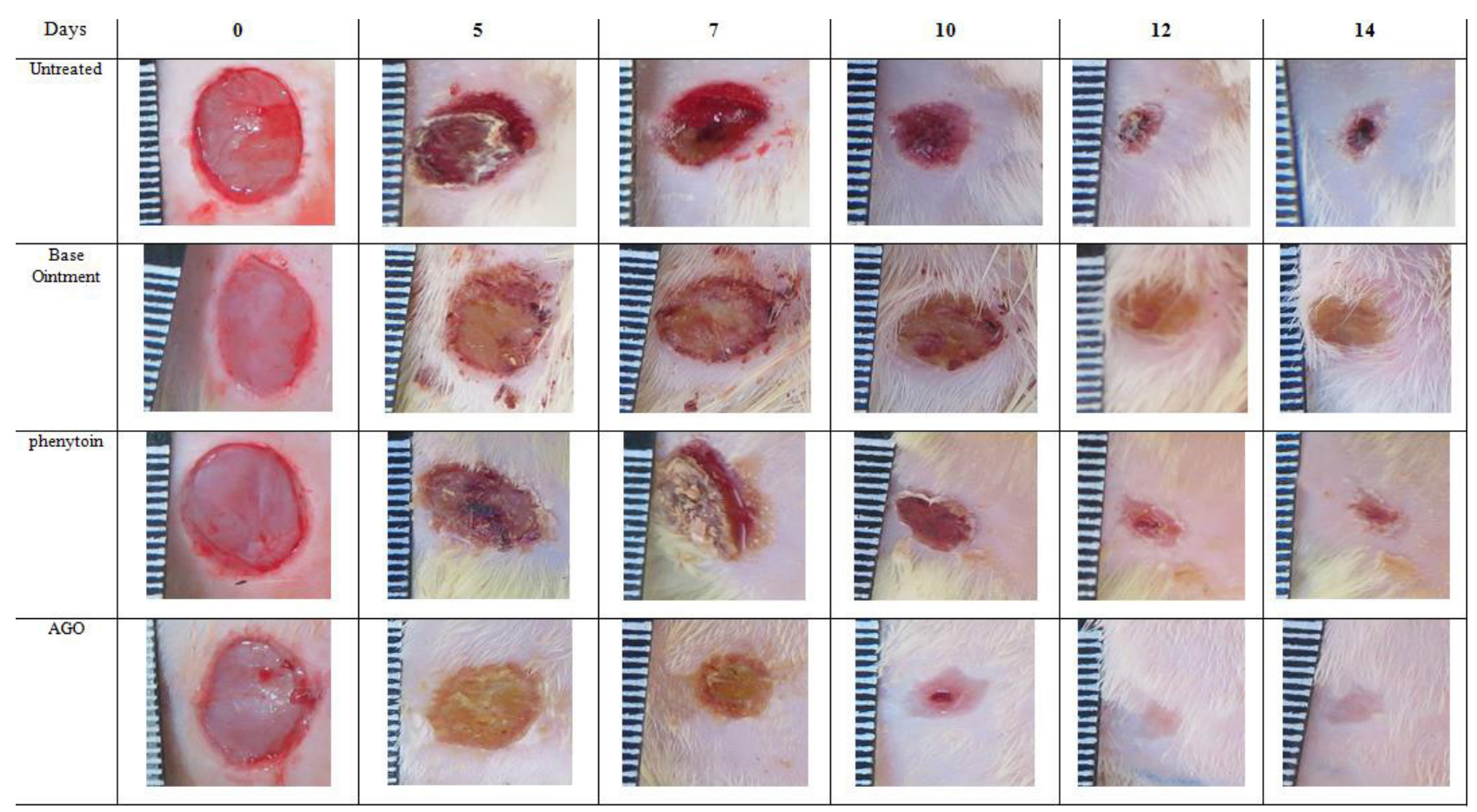

Fig. 1 Representative photographs of the transition of wound closure in the rat model. Untreated; wound surgery only, base ointment; wound topically treated with Base (beeswax and sesame oil), Phenytoin; wound topically treated with phenytoin 1\% cream, AG0; wound topically treated with AGO. 


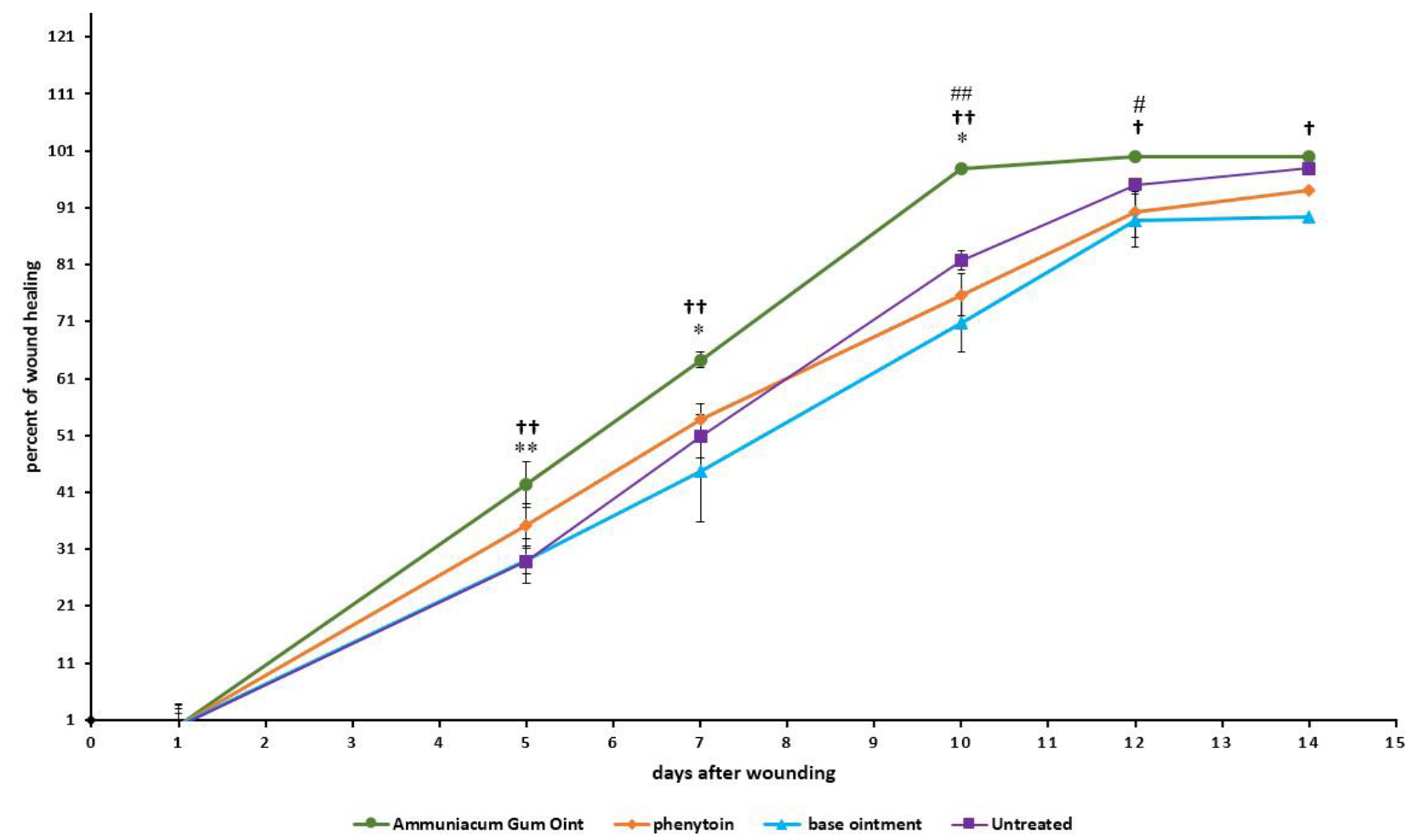

Fig. 2 The percentage of wound healing measured by Digimizer. Values are expressed as mean $\pm \mathbf{S E} ., \mathbf{n}=\mathbf{8}$ in each group.

*: $P<0.05$ vs untreated, ${ }^{* *}: P<0.01$ vs untreated, \#: $P<0.05$ vs phenytoin, \#\#:P<0.01 vs phenytoin, $+: P<0.05$ vs Base treated, $+t: P<0.01$ vs Base treated

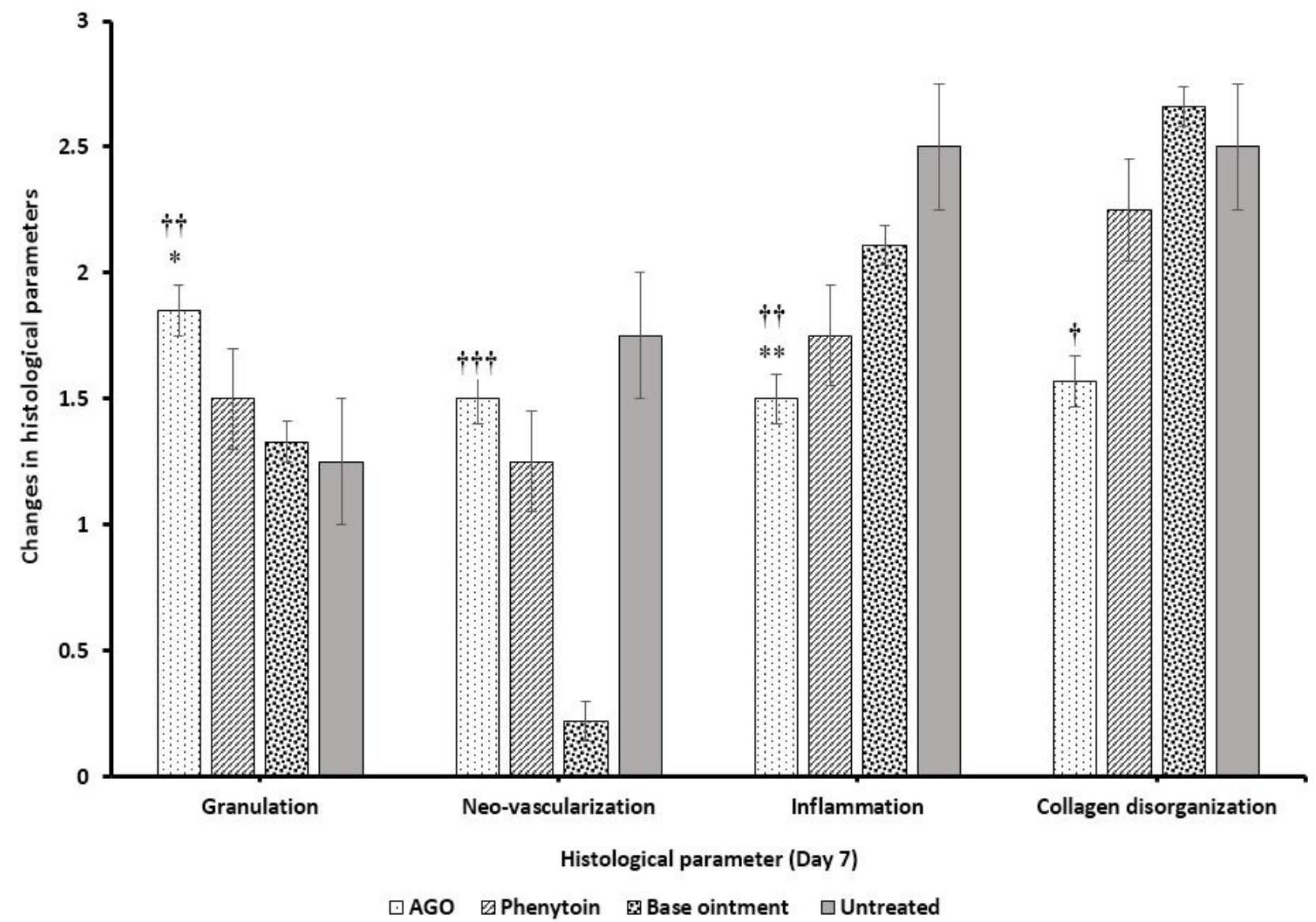

Fig. 3 Comparison of histological parameter in experimental groups on Day 7. Data are expressed as mean \pm SE. $\mathbf{n}=\mathbf{8}$ in each group.

* $P<0$.05: Comparison to untreated groups, $+P<0.05$ : Comparison to base ointment-treated groups. 


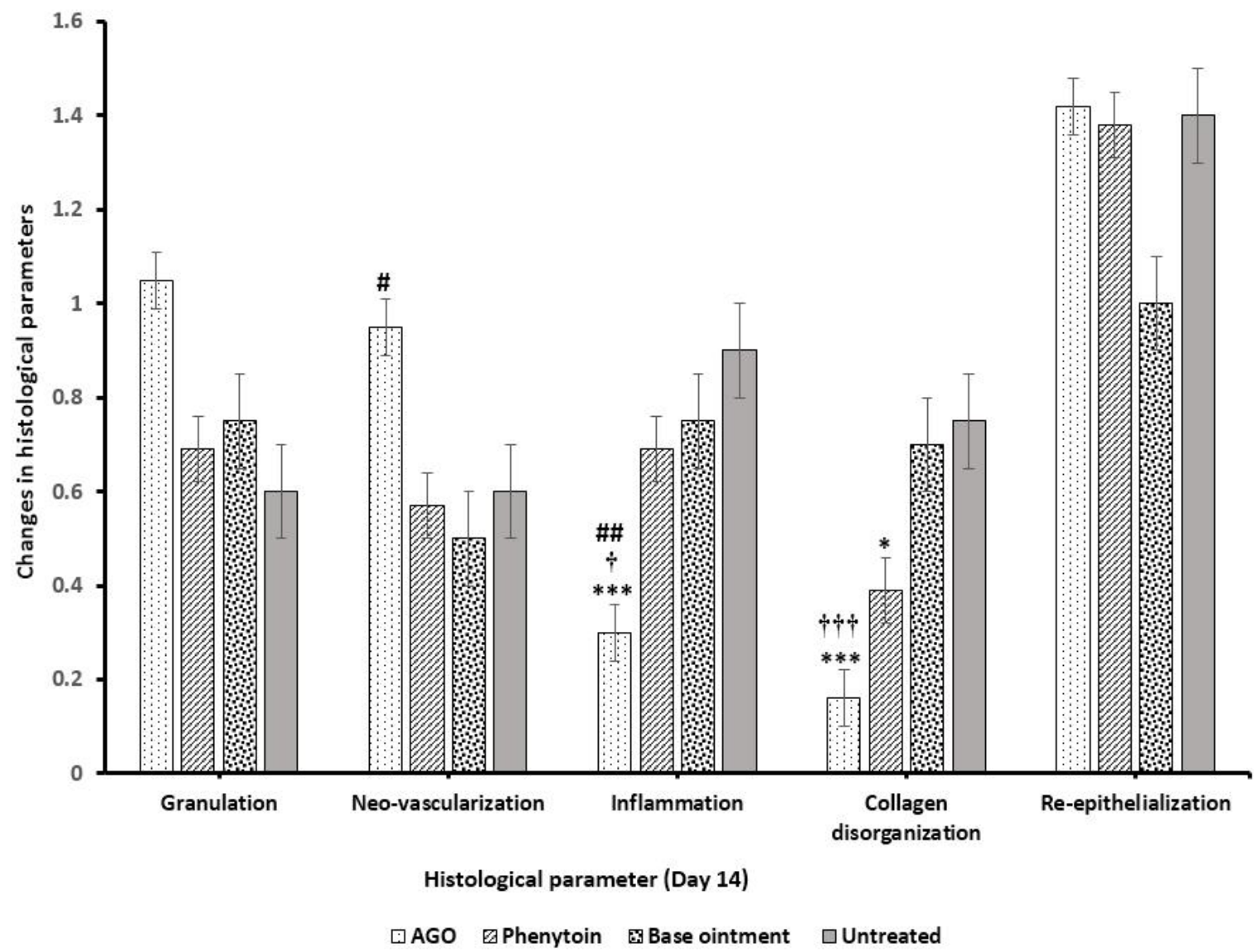

Fig. 4 Comparison of histological parameter in experimental groups on Day 14. Data are expressed as mean \pm SEM. $\mathbf{n}=\mathbf{8}$ in each group.

*: $P<0.05$ vs untreated, ${ }^{* * *}: P<0.001$ vs untreated, $\#: P<0.05$ vs phenytoin, $+: P<0.05$ vs Base ointment-treated, + t: $P<0.01$ vs Base ointment-treated group.

base-treated groups $(P<0.001)$, and phenytoin cream treated group $(P<0.01)$. On the 14 th day, the hydroxyproline content showed a significant increase $(P<0.001)$ in the AGO-treated group compared to all control groups. The results of the hydroxyproline measurement showed in Table 2.

\section{Growth Factors Assay}

In the 7th and 14th days after wounding, the serum level of growth factors (EGF. PDGF, VEGF, TGF-B) in animals treated with AGO showed a significant increase $(P<0.05)$. The results showed in Figs 7-10.

\section{Discussion}

Wound healing is a dynamic process that involves several continuous, overlapping, and carefully designed steps. Interruptions, deviations, or prolongation of this process can lead to delayed wound healing or occur chronic wounds. In adults, wound healing process includes: (1) rapid homeostasis and inflammation; (2) proliferation; and (3) remodeling. ${ }^{29,30}$

Hemostasis begins shortly after the injury, with vasoconstriction and fibrin clots forming. The clot and tissue around the wound release proinflammatory cytokines and growth factors such as TGF- $\beta$, PDGF, fibroblast growth factor, and EGF. When the bleeding controlled, inflammatory cells migrate to the wound site (chemotaxis) and advance the inflammatory phase, which is characterized by the consecutive infiltration of neutrophils, macrophages, and lymphocytes. ${ }^{30,31}$

In the proliferation phase, collagen fibers accumulate and neovascularization occurs, the edges of the wound contracts, the surface of the wound reduces, and then the epithelial tissues produced at the wound site. The main feature of this phase is the collagen deposition in a well-organized network. At this stage, the tensile strength of the tissue enhanced by cross-linking between collagen fibers using vitamin C-dependent hydroxylation..$^{32}$ At this phase, the migration of fibroblasts to the site of the wound increased. ${ }^{31}$

The regeneration stage begins several days after injury and remains up to 2 years, resulting in the completion of normal epithelium and scar tissue maturation. The accumulation and deposition of collagen and other cellular matrix proteins give strength to the healing tissue. However, the repaired tissue never achieves initial tissue strength. As the scar matures, the level of blood vessels decreases and the scar changes over time from red to pink and gray. ${ }^{33}$

Dorema ammuniacum from family Apiaceae is rich in phenolic compounds, and also antioxidant ${ }^{19}$, anti-inflammator $y^{20}$, and antimicrobial ${ }^{21,34}$ effects of this plant have been approved in various studies. The anti-inflammatory activity of this plant is important in the first stage of the wound healing process because increasing the inflammatory phase duration could postpone wound healing. Anti-inflammatory activity is essential to decrease the duration of wound healing 


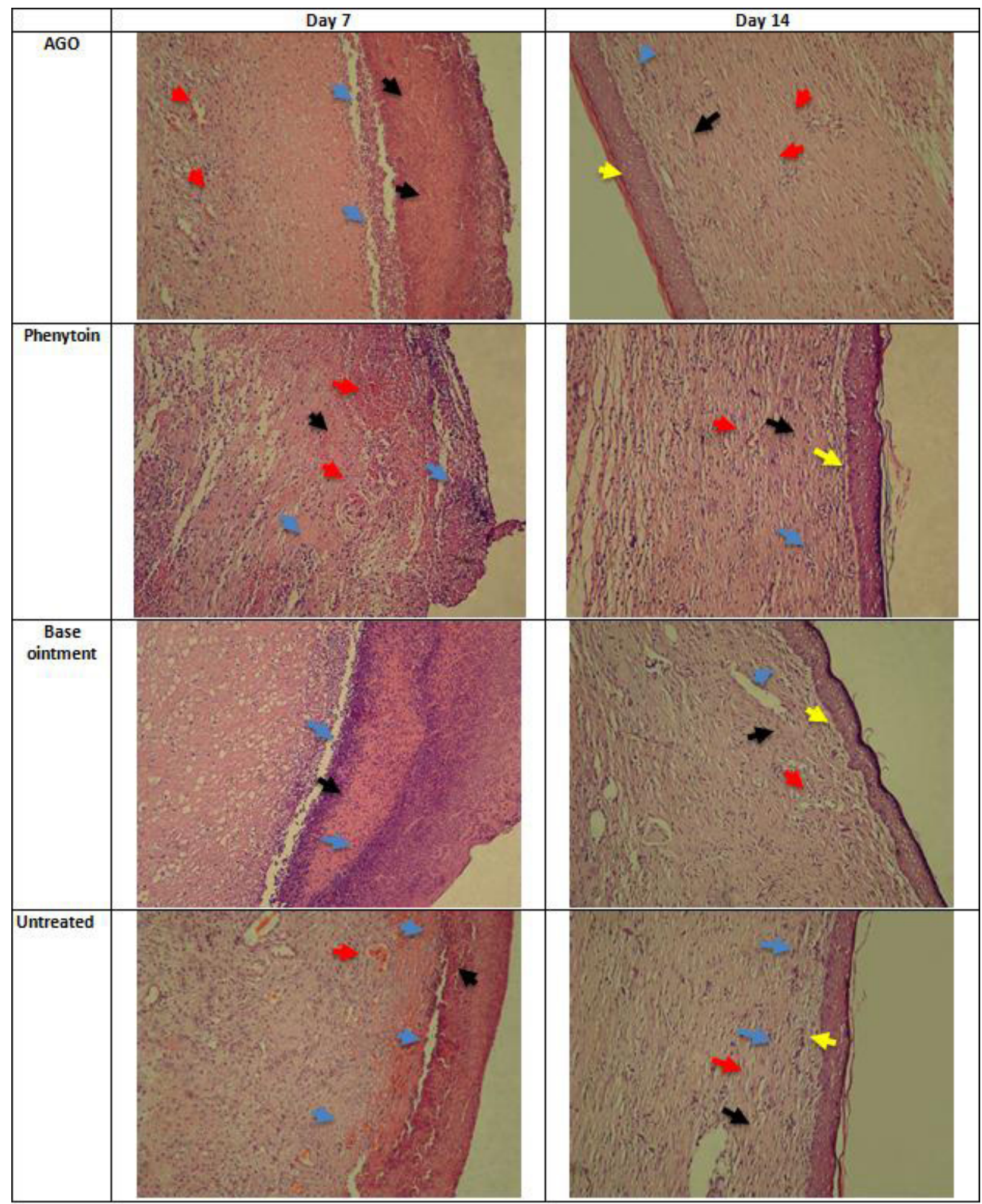

Fig. 5 Representative micrographs of wound healing on days 7 and 14 (HE staining) in AG0, phenytoin, Base oint and untreated group under $\times 40$ magnifications. Granulation (black arrow), neo-vascularization (red arrow), inflammation (blue arrow) and re-epithelialization (yellow arrow).

and reduce pain and scar. In the Iranian traditional medicine books, the effects of this plant have been discussed in the treatment of various types of wounds. In this study, the therapeutic effects of Dorema ammuniacum gum on the wound healing in animals investigated. No study performed on wound healing effects of ammoniacum gum. However, several studies performed on the anti-inflammatory and antibacterial properties of this compound and the therapeutic effects approved. ${ }^{20,34}$

In 2017, Azam Bakhtiarian and colleagues have been studied the analgesic and anti-inflammatory effect of the 


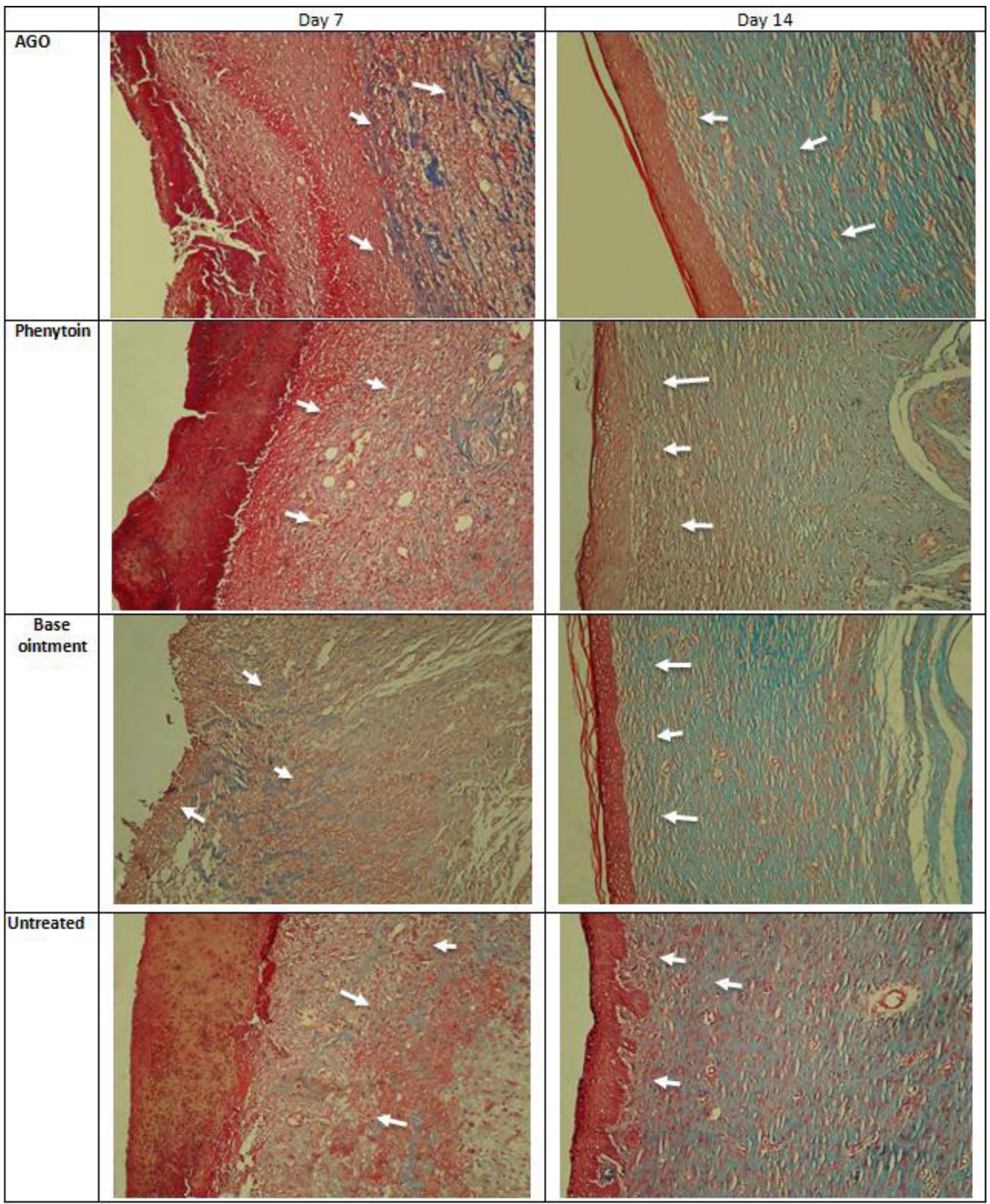

Fig. 6 Representative micrographs of wound healing on Day 7 (trichrome staining) in AG0, phenytoin, Base oint and untreated group. White arrow indicate representative Collagen fibers.

aqueous extract of Dorema ammoniacum gum. The results of this study demonstrated that the gum could decrease the inflammation and pain in experimental rats, in which the anti-inflammatory effect was comparable to indomethacin..$^{20}$

The antibacterial activity of Dorema ammoniacum gum demonstrated by Rajani et al. ${ }^{34}$ In this study, the methanol-dichloromethane extract of ammoniacum gum was assessed against 14 microorganisms which included seven Gram-positive and four Gram-negative bacteria, one yeast, and two fungi. The results showed that the extract of ammoniacum gum inhibited all the seven Gram-positive bacteria, one Gram-negative bacterium, one yeast, and one fungus. ${ }^{34}$ 


\begin{tabular}{|c|c|c|}
\hline \multirow[t]{2}{*}{ Experimental groups } & \multicolumn{2}{|c|}{ Tensile strength $\left(\mathrm{g} / \mathrm{cm}^{2}\right)$} \\
\hline & Day 7 & Day 14 \\
\hline Ammoniacum Gum ointment & $877.33 \pm 33.19$ *** 十†\# & $1511.6 \pm 114.9 * * *$ 十†十\#\# \\
\hline Phenytoin & $724.67 \pm 11.83^{* *}$ & $1078.0 \pm 65.7$ \\
\hline Ointment base & $668.67 \pm 10.17$ & $982.0 \pm 12.1$ \\
\hline No-treatment & $513 \pm 53.69$ & $950.8 \pm 28.5$ \\
\hline
\end{tabular}

It has been reported that TGF-B promotes differentiation of fibroblast to myofibroblasts, which is essential for wound contraction. PDGF can induce matrix metalloproteinase secretion from fibroblasts. ${ }^{35}$ In 2016, João De Masi et al. studied the therapeutic effect of growth factors on wound healing in rats. The data showed that the injection of growth factors in the margin of the wound can accelerate wound healing. ${ }^{36}$

This study showed that the wound area in the treated group with AGO was significantly reduced compared to the phenytoin treated and untreated groups on different days. The results of imaging confirmed that the treatment with ammoniacum ointment accelerated healing and decreased wound area so that on the 12th day after the wounding, all animals which treated with this medicine had completely healed.

The data obtained from the histological test indicate that the topical application of ammoniacum gum accelerated the formation of granulation tissue in the early stages of wound healing which accelerates wound healing. The ammoniacum gum probably accelerated wound healing by rapidly increasing granulation and epithelialization due to increased PDGF and EGF, respectively. Also, AGO increased vascularization and production of epithelial tissue as well as the keratinized layer in these animals on the 14th day.

The results of tensile strength and hydroxyproline content of repaired skin on the 7th and 14th days after wounding showed that the use of ammoniacum ointment increased the skin strength. Also, the results of the histological parameters confirm that in the treated group the amount of oriented collagen fibers at the wound area, which increases the skin firmness, is significantly increased compared to the control groups.

\section{Conclusion}

The results of this study showed that ammoniacum gum increased hydroxyproline content, tensile strength, and serum level of growth factors, and accelerated wound closure, increased the rate of granulation and neovascularization in AGO-treated animals. Since granulation tissue formation and collagen production in the early stages of wound healing is essential for tissue regeneration, accelerated granulation tissue formation and collagen replacement in the first days of wound healing is one of the causes of rapid healing and wound closure after topical application of AGO compared to control groups.

\section{Acknowledgment}

This research was supported by Jundishapur University of Medical Sciences, Ahvaz, Iran. The code of ethics IR.AJUMS. ABHC.REC.1397.039. Work was also performed at the Medicinal Plant Research Centre of Jundishapur University of Medical Sciences, Ahvaz, Iran.

\section{Table 2. Comparison of hydroxyproline content in wound tissue sample} after treatment.

\begin{tabular}{lll}
\hline & \multicolumn{1}{c}{$\begin{array}{c}\text { Day } 7 \\
\text { Mean } \pm \text { SEM }\end{array}$} & \multicolumn{1}{c}{$\begin{array}{c}\text { Day 14 } \\
\text { Mean } \pm \text { SEM }\end{array}$} \\
\hline AGO & $13.8100 \pm 0.33005^{* *}+\dagger \#$ & $28.5340 \pm 0.99748^{* *}+\dagger \#$ \\
Phenytoin & $12.0733 \pm 0.48340^{* *}$ & $22.2060 \pm 0.40783^{*}$ \\
Ointment base & $7.7100 \pm 0.33171$ & $18.7640 \pm 0.31706$ \\
No-treatment & $8.8300 \pm 0.18930$ & $19.7340 \pm 0.30323$ \\
\hline
\end{tabular}

Significant differences from untreated, phenytoin and base treatment groups:

*: $P<0.01$ vs untreated, ${ }^{* *}: P<0.001$ vs untreated; $\#: P<0.01$ vs phenytoin, $\# \#: P<0.001$ vs phenytoin; $++: P<0.001$

vs Base treated. 


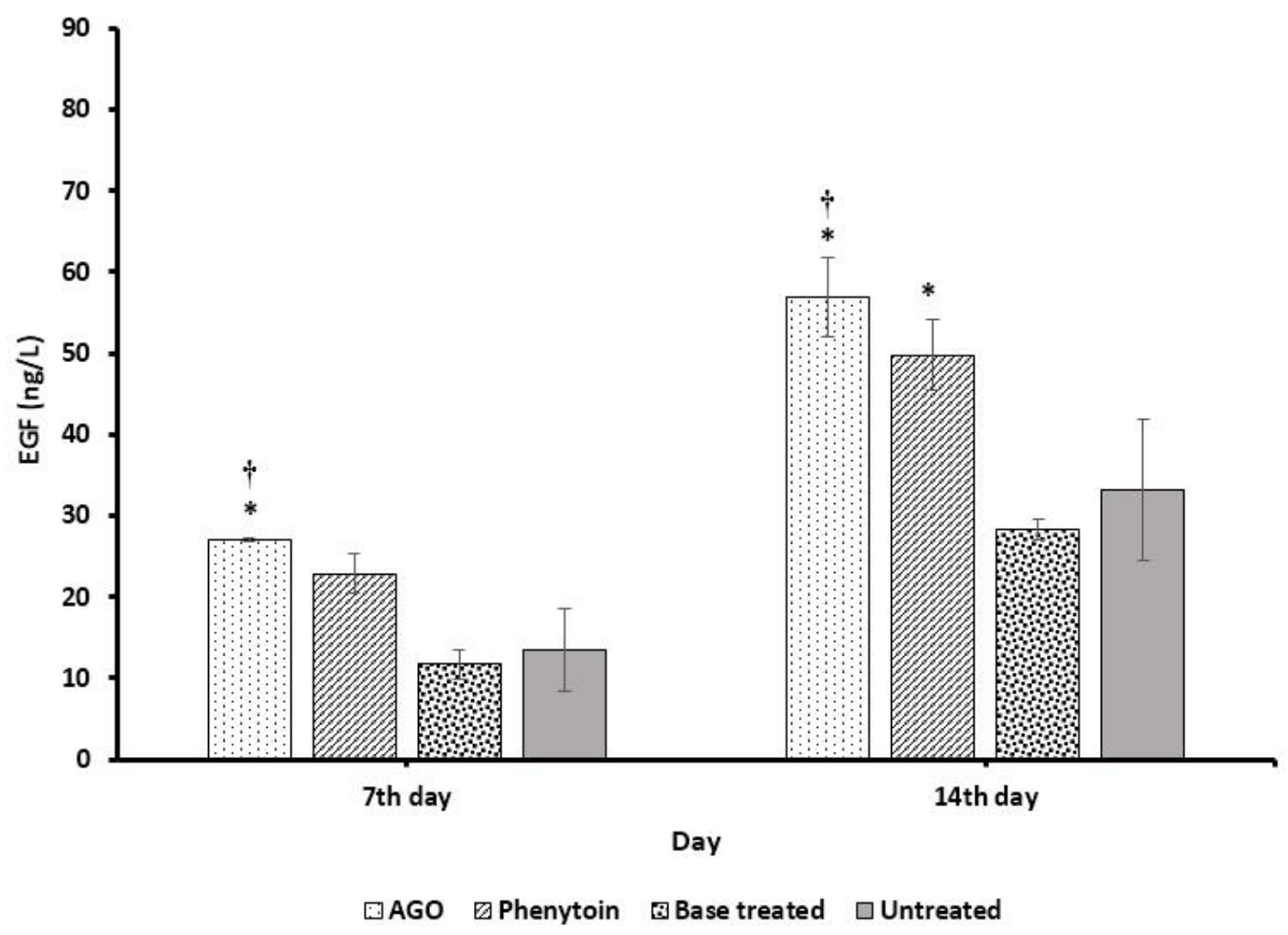

Fig. 7 Comparison of serum levels of EGF in experimental groups. Data are expressed as mean \pm SE. $\mathbf{n}=\mathbf{8}$ in each group.

$+P<0.05$ indicate that values are significantly different from base ointment-treated group.

* $P<0.05$ indicate that Values are significantly different from untreated group.

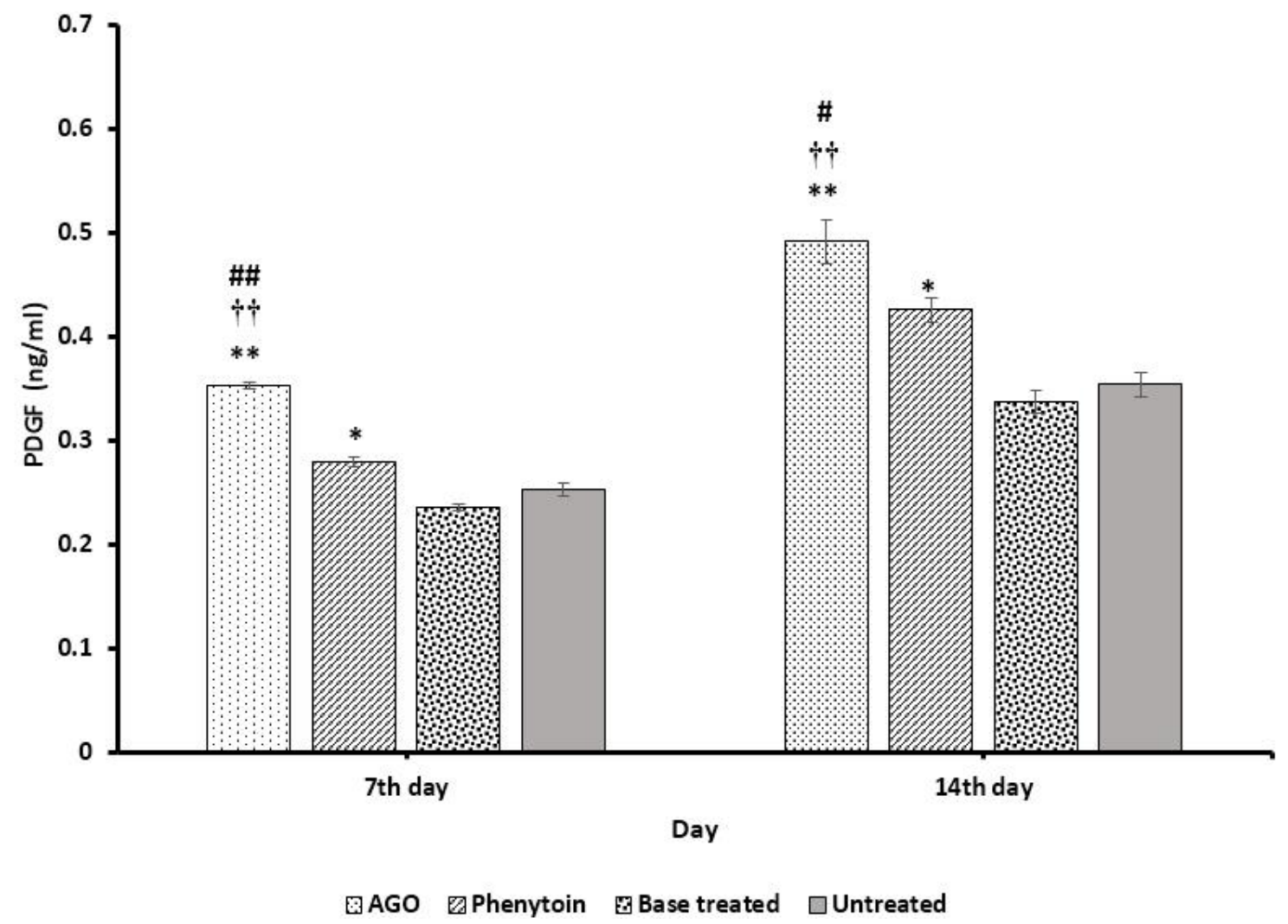

Fig. 8 Comparison of serum levels of PDGF in experimental groups. Data are expressed as mean $\pm \mathrm{SE}$.

$\mathbf{n}=\mathbf{8}$ in each group.

*: $P<0.01$ vs untreated, **: $P<0.001$ vs untreated, $\#: P<0.01$ vs phenytoin, \#\#: $P<0.001$ vs phenytoin, $++: P<0.001$ vs Base treated. 


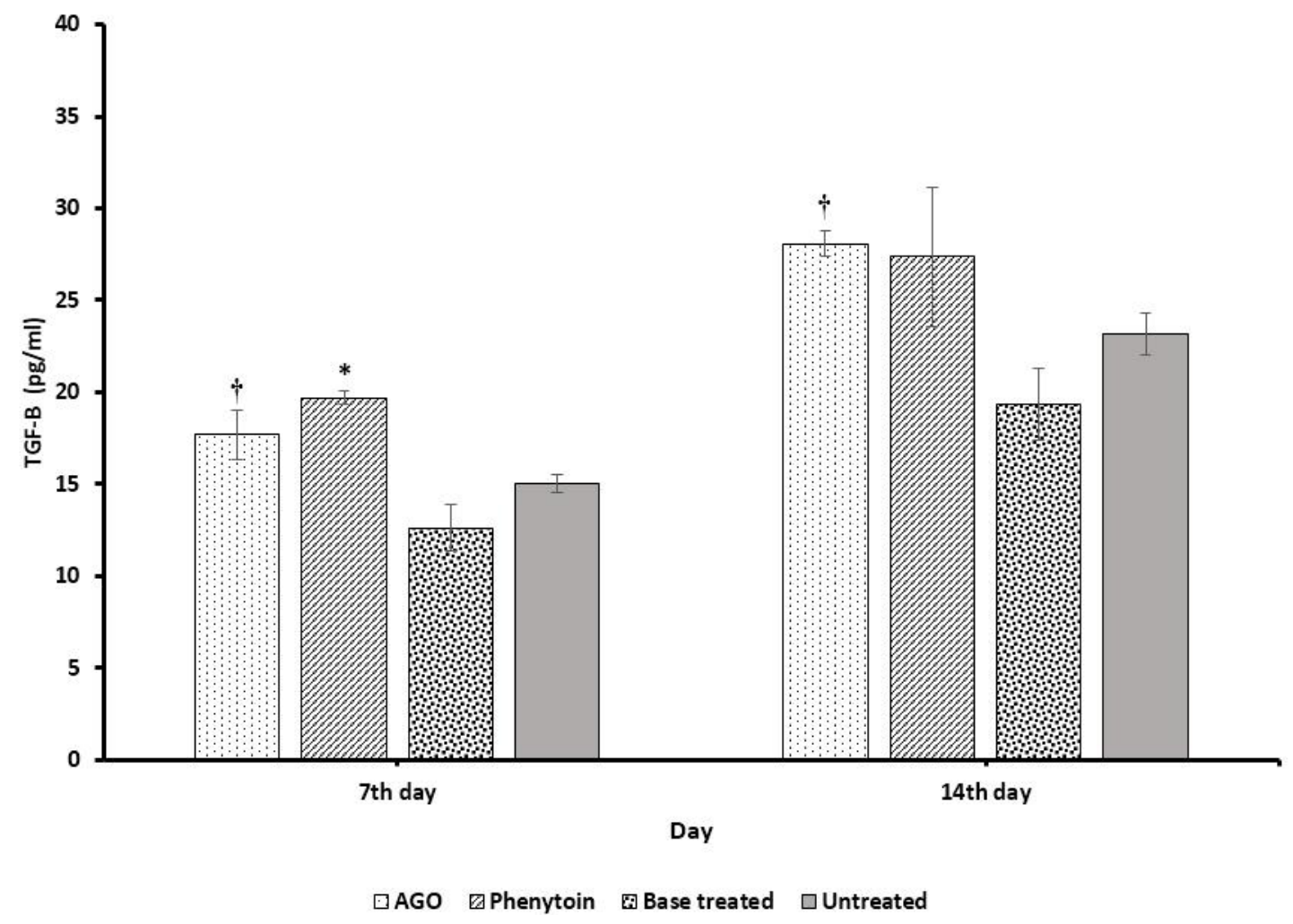

Fig. 9 Comparison of serum levels of TGF-B in experimental groups on days 7 and 14 after wounding. Data are expressed as mean \pm SE. $\mathrm{n}=\mathbf{8}$ in each group.

* $P<0.05$ : Values significantly different from untreated group; $\uparrow P<0.05$ : Values significantly different from Base ointment-treated group.

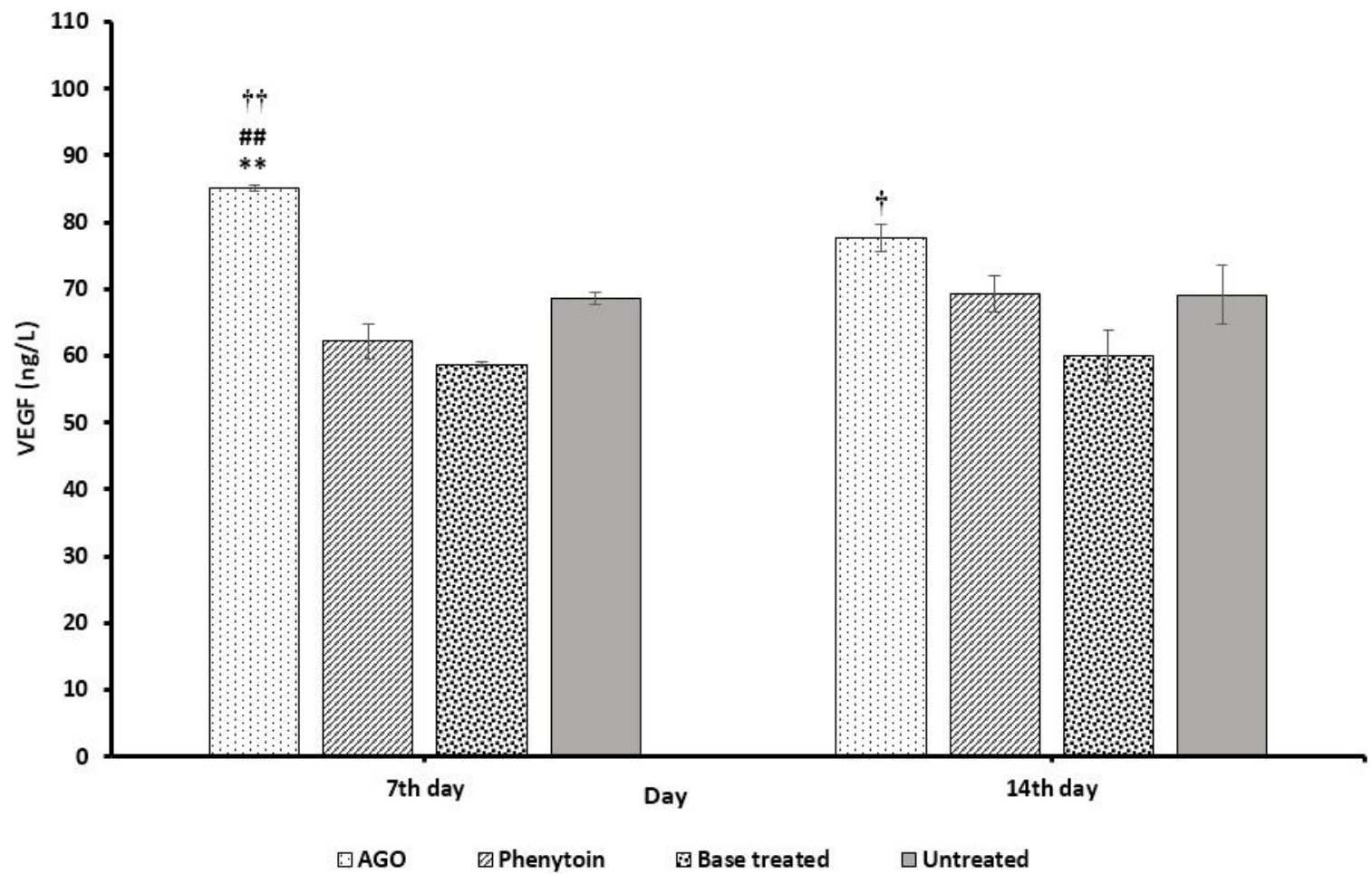

Fig. 10 Comparison of serum levels of VEGF in experimental groups. Data are expressed as mean $\pm \mathbf{S E}$. $\mathbf{n}=\mathbf{8}$ in each group.

$* *: P<0.001$ vs untreated, $\# \#: P<0.001$ vs phenytoin, $+: P<0.05$ vs Base treated, $++: P<0.001$ vs Base treated. 


\section{Conflict of Interest}

The authors declare that there is no known conflict of interest regarding this publication.

\section{References}

1. Lazarus GS, Cooper DM, Knighton DR, Margolis DJ, Percoraro RE, Rodeheaver $\mathrm{G}$, et al. Definitions and guidelines for assessment of wounds and evaluation of healing. Wound Repair Regen. 1994;2(3):165-70.

2. Attinger CE, Janis JE, Steinberg J, Schwartz J, Al-Attar A, Couch K. Clinical approach to wounds: debridement and wound bed preparation including the use of dressings and wound-healing adjuvants. Plastic Reconst Surg. 2006:117(7S):72S-109S

3. George Broughton I, Janis JE, Attinger CE. Wound healing: an overview. Plastic Reconst Surg. 2006;117(7S):1e-S-32e-S.

4. Hunt TK. The physiology of wound healing. Ann Emerg Med. 1988:17(12):1265-73.

5. Robson MC, Steed DL, Franz MG. Wound healing: biologic features and approaches to maximize healing trajectories. Curr Probl Surg. 2001;2(38): 72-140.

6. Mirmalek SA, Parsa T, Parsa Y, Yadollah-Damavandi S, Salimi-Tabatabaee SA Jangholi $E$, et al. The wound healing effect of Iris forentina on full thickness excisional skin wounds: A histomorphometrical study. Bangl J Pharmacol. 2016;11(1):86-90

7. Shen H-M, Chen C, Jiang J-Y, Zheng Y-L, Cai W-F, Wang B, et al. The N-buty alcohol extract from Hibiscus rosa-sinensis L. flowers enhances healing potential on rat excisional wounds. J Ethnopharmacol. 2017;198:291-301.

8. Nicolaus C, Junghanns S, Hartmann A, Murillo R, Ganzera M, Merfort I. In vitro studies to evaluate the wound healing properties of Calendula officinalis extracts. J Ethnopharmacol. 2017;196:94-103.

9. Joshi A, Joshi VK, Pandey D, Hemalatha S. Systematic investigation of ethanolic extract from Leea macrophylla: Implications in wound healing. J Ethnopharmacol. 2016;191:95-106.

10. Pereira LdP, Mota MR, Brizeno LA, Nogueira FC, Ferreira EG, Pereira MG, et al. Modulator effect of a polysaccharide-rich extract from Caesalpinia ferrea stem barks in rat cutaneous wound healing: Role of TNF- $a, I L-1 \beta, N O, T G F-\beta$. J Ethnopharmacol. 2016;187:213-23.

11. Krishnappa P, Venkatarangaiah K, Rajanna SKS, Balan RK. Wound healing activity of Delonix elata stem bark extract and its isolated constituent quercetin-3-rhamnopyranosyl-(1-6) glucopyranoside in rats. J Pharm Analy. 2016;6(6):389-95.

12. Öz BE, Ilhan M, Ozbilgin S, Akkol EK, Acikara ÖB, Saltan G, et al. Effects of Alchemilla mollis and Alchemilla persica on the wound healing process. Bangl J Pharmacol. 2016;11(3):577-84.

13. MH AKS. qarabadin e kabir (great qarabadin). Tehran, Iran: Tehran University of Medical Science.

14. MH AKS. Makhzan-al-Advieh (The Storehouse Medicaments): Encyclopedia of Traditional Iranian Foods and Drugs (Old Times). Calcutta, India: Tehran University of Medical Sciences; 1844. 1081 p.

15. Trease G, Evans W. Pharmacognosy (13th edn). Bailliere Tindall, London. 1989:176-80.

16. Mozaffarian V, Mozaffarian V, Mozaffarian V. Dictionary of Iranian plant names. 1996.
17. Langenheim JH. Plant resins: Chemistry, evolution, ecology, and ethnobotany: Oregon, US: Timber Press; 2003.

18. Yousefzadi M, Heidari M, Akbarpour M, Mirjalili MH, Zeinali A, Parsa M. In vitro cytotoxic activity of the essential oil of Dorema ammoniacum D. Don. Middle-East J Sci Res. 2011;7(4):511-4.

19. Delnavazi M, Tavakoli S, Rustaie A, Batooli H, Yassa N. Antioxidant and antibacterial activities of the essential oils and extracts of Dorema ammoniacum roots and aerial parts. Res J Pharmacogn. 2014;1(4):11-8.

20. Bakhtiarian A, Shojaii A, Hashemi S, Nikoui V. Evaluation of analgesic and antiinflammatory activity of Dorema ammoniacum gum in animal model. Int J Pharm Sci Res. 2017:8(7):3102-6.

21. Kumar VP, Chauhan NS, Padh H, Rajani M. Search for antibacterial and antifungal agents from selected Indian medicinal plants. J Ethnopharmacol. 2006;107(2):182-8

22. Motevalian M, Mehrzadi S, Ahadi S, Shojaii A. Anticonvulsant activity of Dorema ammoniacum gum: Evidence for the involvement of benzodiazepines and opioid receptors. Res Pharm Sci. 2017;12(1):53.

23. Adhami H-R, Lutz J, Kählig H, Zehl M, Krenn L. Compounds from gum ammoniacum with acetylcholinesterase inhibitory activity. Sci Pharm. 2013:81(3):793-806.

24. SHAHIDI GH, Moein MR, Foroumadi AR, Rokhbakhsh ZF. Cytotoxic activity of medicinal plants used in Iranian traditional medicine on two strains of Saccharomyces cerevisiae. 2002

25. Cross S, Naylor L, Coleman R, Teo T. An experimental model to investigate the dynamics of wound contraction. Br J Plastic Surg. 1995:48(4):189-97.

26. Woessner Jr J. The determination of hydroxyproline in tissue and protein samples containing small proportions of this imino acid. Arch Biochem Biophysics. 1961;93(2):440-7.

27. Edwards C, O'Brien JrW. Modified assay for determination of hydroxyproline in a tissue hydrolyzate. Clin Chim Acta. 1980;104(2):161-7.

28. Fried NM, Walsh Jr JT. Laser skin welding: in vivo tensile strength and wound healing results. Lasers Surg Med Off J Am Soc Laser Med Surg. 2000;27(1):55-65.

29. Firdous SM, Sautya D. Medicinal plants with wound healing potential. Bangl J Pharmacol. 2018;13(1):41-52

30. Gosain A, DiPietro LA. Aging and wound healing. World J Surg. 2004;28(3):321-6.

31. George Broughton I, Janis JE, Attinger CE. The basic science of wound healing. Plastic Reconst Surg. 2006;117(7S):12S-34S.

32. Guo Sa, DiPietro LA. Factors affecting wound healing. J Dent Res. 2010;89(3):219-29.

33. Young A, McNaught C-E. The physiology of wound healing. Surgery (Oxford). 2011:29(10):475-9.

34. Rajani M, Saxena N, Ravishankara M, Desai N, Padh H. Evaluation of the antimicrobial activity of ammoniacum gum from Dorema ammoniacum Pharm Biol. 2002:40(7):534-41

35. Barrientos S, Stojadinovic O, Golinko MS, Brem H, Tomic-Canic M. Growth factors and cytokines in wound healing. Wound Repair Regen 2008;16(5):585-601.

36. De Masi ECDJ, Campos ACL, De Masi FDJ, Ratti MAS, Ike IS, De Masi RDJ. The influence of growth factors on skin wound healing in rats. Braz Otorhinolaryngol. 2016;82(5):512-21.

This work is licensed under a Creative Commons Attribution-NonCommercial 3.0 Unported License which allows users to read, copy, distribute and make derivative works for non-commercial purposes from the material, as long as the author of the original work is cited properly. 